\title{
Lost for Words: Instructional Approaches to Support Older Struggling Writers
}

\author{
Debra Myhill and Susan Jones
}

Mastering the art of writing is an essential pre-requisite for social and economic well-being in twenty-first century Western society. New digital technologies, including social media, have vastly increased the significance of writing as a mode of communication, both socially and in the workplace. Twitter can start revolutions, WikiLeaks can expose criminals and, at a more mundane level, emails are now the ubiquitous form of communication within most institutions. Perhaps more significantly for this chapter, writing remains stalwartly the gatekeeper to educational success: almost all examinations are required to be handwritten, and in England, revisions to public examinations have generated an increased emphasis on terminal written examinations. In this context, any child or young person who is unable to communicate effectively in writing is disadvantaged.

Yet research repeatedly tells us how difficult writing is to master. The National Commission on Writing in America's Schools and Colleges (2003) maintained that "writing is best understood as a complex intellectual activity that requires students to stretch their minds, sharpen their analytical capabilities and make valid and accurate distinctions" (2003, p. 13). This complexity is multi-layered. From a cognitive perspective, writing is a costly activity (Alamargot \& Chanquoy, 2001; Kellogg, 1994), making high demands on working memory, and tying up mental resources (Sharples, 1999). Indeed, Kellogg (2008) has argued that writing is more cognitively demanding than playing chess. Linguistically, writing is more complex than speech: it contains more subordination, greater lexical density, more embeddedness, more passives, and demands a wider range of vocabulary than speech (Czerniewska, 1992); young writers have to learn the differences between writing and spoken language. Furthermore, writing is a social practice (Prior, 2005), where what is valued in writing and how written texts are shaped varies from community to community and by situation. Young writers have to learn the social and cultural aspects of texts, as well as simply being able to reproduce them (Kress, 1994). Finally, the nature of the writing task itself can affect its demands: a transactional note to a friend reminding him or her to feed the cat is less complex and demanding than writ-

(C) KONINKLIJKE BRILL NV, LEIDEN, 2018 | DOI: 10.1163/9789004346369_009

This is an open access chapter distributed under the terms of the prevailing CC-BY-NC License at the time of publication. 
ing an argument about a topic which requires both knowledge and control of topical information, and the ability to express intellectual reasoning in written form. And as Nelson and Gregg note in Chapter 5, struggling to master school writing may be paralleled with success in out-of-school literacies.

On one level, then, all writers struggle with writing. Expert writers do not necessarily find writing easy, and as proficiency in writing grows, so too do writers' expectations of their text. Whilst very young writers are struggling with the most basic acts of motor control of a pencil, letter shaping and word spacing, mature writers are battling with shaping the text to fit sophisticated rhetorical intentions. In a recent interview with Booker prize winner, Hilary Mantel, for a study on the composing processes of professional writers, she explained her sense of what she could or could not write well:

I think I am always trying new things, but the reason for that is that that's a very powerful question to me, and I think to be honest there probably are things I really can't do. I remember having this conversation with a writer long ago and I said to her 'I need to write a battle' and she said 'I need to write a dinner party'. ((Laughter)) You know, her object, was to have eight people on the page, mine was to have eighty thousand but I still haven't written a battle, and I am very conscious that despite what people call the epic scale of my fiction I do tend to push it into holes and corners. I write the head-to-head and I write the smoky back room. I can write the arena but I've not taken it outdoors, and I am more at ease with the peopled world than with the natural world. I am working on that. So you're conscious of your limitations and pushing against them.

This chapter, however, is specifically concerned with that group of writers in secondary schools who would be regarded as struggling when compared with typically developing writers. This includes children with specific language impairments (SLI) and those with no identified special need but whose attainment in writing is significantly below the average for that age group. In this chapter we will first offer an overview of what existing research has revealed about struggling writers. We will then consider evidence-based instructional approaches deemed to support struggling writers, with a particular focus on two studies we have conducted which resulted in improved student outcomes in writing. Finally, the chapter concludes with a consideration of implications for further research. 


\section{The Characteristics of Writing in Struggling Writers}

Empirical understanding of writing development (the process of writing and how writing is mastered) remains dwarfed by the much more substantive parallel body of work on reading (Myhill \& Fisher, 2010). Nevertheless, there is a well-developed, albeit small, body of research about children who struggle with writing (see also Chapter 5 of this book for a discussion of some of these difficulties in adolescents and adults). There seems to be general agreement on the characteristics of texts from children with writing difficulties: Typically they are short and not confidently organised (Garcia \& Fidalgo, 2008; Hooper, Swartz, Wakely, de Kruif, \& Montgomery, 2002; MacArthur \& Graham, 1987); likely to contain a substantial number of errors in spelling, punctuation and grammar (Graham, 1990); and the handwriting is likely to be only poorly legible and executed slowly (Graham \& Weintraub, 1996). In addition, De Milliano, van Gelderen, and Sleegers (2012) found that struggling writers are more likely to exhibit the kind of writing consistent with the knowledge-telling phase, as described by Bereiter and Scardamalia (1987). These characteristics point to writers who developmentally appear to be hampered by the need to focus on transcription of ideas in the head to words on the page. Bereiter and Scardamalia (1982) argue that the capacity to think globally about the text as a whole is constrained by the local demands of transcription and generating the next sentence and that "until such co-ordination of goals and composing strategies is achieved, we suspect children cannot do much to shape or improve their compositions at the 'macro' level" (p. 6).

The importance of metacognitive knowledge as an enabling factor in writing is signalled many times in the literature (Alamargot \& Chanquoy, 2001; Hayes \& Flower, 1980; Kellogg, 1994; Martlew, 1983). Metacognitive knowledge supports the writer in managing the writing process strategically and in decision-making during writing. A subset of metacognition is metalinguistic knowledge, and this plays a key role in writing in facilitating lexical, syntactic and pragmatic choices about the emerging text. It seems, however, that struggling writers are less strong in these areas. Both Troia (2006) and Garcia and Fidalgo (2008) found that writers with learning difficulties had less metaknowledge than their peers. Drawing on Bialystok and Ryan's (1985) conceptualisation of metalinguistic knowledge as analysis and control, where analysis represents the ability to represent explicit, conscious linguistic knowledge and control is the ability to selectively attend to and apply that knowledge, Lum and Bavin (2007) conducted a study which found that children with SLI had more difficulty with metalinguistic tasks requiring analysis and control than did their typically developing peers. 
However, the research considered thus far is predominantly conducted with younger writers in the primary phase. There is a dearth of research which addresses struggling writers in the adolescent stage, or older. A small-scale study by Sawyer, Francis and Knight (1992) investigated special arrangements at General Certificate of Secondary Education (GCSE) for candidates with specific learning difficulties, and the basis upon which extra time is given. The study examined the predictive validity of short tests as an alternative assessment model. A more substantive study by Dockrell, Lindsay \& Connelly (2009) tracked the writing performance of 58 students with SLI, collecting assessment data over five time points from age 8 to age 16 years in order to determine longitudinal trajectories in writing performance and to investigate the relationships between written and oral language, reading and handwriting fluency. They found that at age 16, this group of struggling writers presented writing with short texts, poor sentence structure and poor organisation. Weaknesses were also evident in handwriting fluency, vocabulary and spelling. What is perhaps surprising about these results is that the characteristics of a struggling writer at age 16 mirror very closely the characteristics of struggling writers in the primary school.

\section{Commonalities and Differences between Specific Language Difficulties and General Delay in Writing}

In addition to research which investigates the characteristics of writing produced by struggling writers, there is a small body of research which explores similarities and differences between writers with SLI and those who lag behind the norm of achievement in writing for their age group. Mackie and Dockrell (2004) analysed the writing performance of three groups: an SLI group of 11year-old students and two comparison groups, one matched for attainment (language attainment of age 7.3 years), and one for chronological age. On writing assessment, the sLI group produced more syntactic errors than the two comparison groups and wrote shorter texts than the chronological age matched group. However, they did not differ in terms of spelling errors or content of written language from the language attainment group. Mackie and Dockrell (2004) concluded that the inter-relationships between oral language, reading and writing differed for the three groups.

Puranik, Lombardino, and Altman (2007) focus specifically on investigating differences in written production among students with and without dyslexia and those with language-impairment. Examining the writing of expository text in students aged 11-21, they analysed language performance at text, sentence 
and word levels. Their results showed that, as might be expected, students without dyslexia performed better than both students with dyslexia or SLI on all measures. Students with dyslexia outperformed those with SLI on a number of variables including the number of T-units (usually defined as a main clause plus any subordinate clauses linked to it), the number of ideas, text length, and lexical variety, although both of these groups performed similarly in spelling and grammatical correctness. Puranik et al. argued that these results support the view that students with dyslexia and SLI differ principally in the non-phonological dimensions of language. Another study comparing students with and without dyslexia (Kinder \& James, 2012) considered authorial identity in university students. Kinder and James adopted a mixed-methods approach. A questionnaire measured self-rated confidence in writing; understanding of authorship; knowledge to avoid plagiarism; top-down, bottom-up and pragmatic approaches to writing; and deep, surface and strategic approaches to learning. They also conducted qualitative interviews with students with dyslexia. The results indicated that students with dyslexia were less strategic in their approach to writing, more likely to adopt surface approaches, less confident about their writing, and less assured in their understanding of authorship. The interviews revealed students' perceptions that being dyslexic made writing more difficult and reduced their sense of confidence in being writers.

This small body of research is both patchy and inconclusive and often conducted with very small samples. Thus, it is hard to determine whether differences between writers with SLI and those who are developmentally delayed are substantive or consistently realised. This leaves open to further empirical investigation the question of whether teaching interventions need to be specifically designed for different groups of struggling writers or whether common approaches can be used. Santangelo and Olinghouse (2009), in a review of research on effective instructional strategies for students with writing difficulties, argue that their concluding recommendations about effective practices are relevant to all students, not just those with writing difficulties. It is beyond the scope of this chapter to address in depth the equally important issues of motivation and self-efficacy (this is addressed by Nelson and Gregg in Chapter 5). Nonetheless, it is clear that by the time struggling writers are in their teen years, they are likely to have experienced several years of "failing" as writers and a growing awareness of the gap between their own writing competence and that of peers, with consequential impact on self-efficacy and motivation. De Milliano et al.'s study (2012) showed that struggling writers who put more effort into their writing achieved more highly than those who were less effortfulan unsurprising finding, perhaps, but one which underlines the importance of considering motivation in this particular age group. It is clear that there 
is potential for substantially more research which focuses on writers in the secondary phase, and which considers not only developmental trajectories in different groups, but also how those trajectories are influenced by changing motivation levels and sense of self-efficacy.

\section{Instructional Approaches to Support Adolescent Struggling Writers}

There have been several substantial reviews or meta-analyses which synthesise research on effective instructional strategies to support struggling writers. Santangelo and Olinghouse (2009) conducted a narrative review, synthesising contemporary qualitative and quantitative research related to effective writing instruction. The Department for Education (DFE) in England (2012) commissioned a review of research evidence on writing, which included a section on approaches for struggling writers and students with Special Educational Needs or Disabilities. More recently, Gillespie and Graham (2014) conducted a meta-analysis of 43 studies, which comprised 35 studies involving students in upper elementary and middle grades, 5 high school studies, and 3 of students in primary grades. Ebbels (2014) considered specifically the effectiveness of interventions to support grammatical competence in school-aged children with language impairments. Inevitably, all of these studies tend to draw on the same body of research and draw broadly similar conclusions. One is that the evidence base is limited, particularly for older school students. The DFE (2012) review noted that "there is little evidence on specific interventions to help pupils with writing, and little evidence on interventions for secondary school pupils" (2012, p. 6), whilst Gillespie and Graham (2014) raise important concerns not simply about the quantity of research, but also its quality and limitations on its generalizability. What is evident, however, is that struggling writers need direct and specific teaching support. Table 8.1 summarises the key conclusions from these reviews.

Considering all these reviews, three instructional approaches do appear to stand out as particularly salient: first, the need to support understanding and skills in managing the writing process; second, the efficacy of strategy instruction; and finally, the value of direct and explicit instructional approaches. It is also important to note that there is considerable overlap among these three categories; for example, one explicit approach might be providing clear prompts for how to revise a text, which overlaps with the writing process.

Troia (2006) notes that children with language difficulties frequently have problems managing the writing process, a point reiterated by Mason, Harris, and Graham (2011). Writing is a complex act, and even when transcription and 


\begin{tabular}{ll} 
Author/s & Conclusions/recommendations \\
\hline Santangelo \& & - establishing a context for effective writing instruction; \\
Olinghouse & - the use of research-based instructional methods and \\
$($ 20o9) & practices; \\
& - teaching strategies in writing; \\
- & teaching level skills such as word, sentence, and \\
& paragraph. \\
- & cognitive strategy instruction; \\
Eepartment for & - explicit, interactive, scaffolded instruction in planning, \\
& composing and revising strategies; \\
- & one-to-one tutoring; \\
- & cross-over effects from national interventions on \\
& reading and formative assessment. \\
- & strategy instruction; \\
- & dictation; \\
- & goal setting; \\
Gillespie \& & process writing. \\
Graham (2014) & - implicit methods for younger children; \\
- & explicit methods for older children.
\end{tabular}

orthography have become reasonably automated, young writers still need to attend to both the content of their intended text and how best to communicate that content in written form. One element of this is understanding that the process of writing incorporates planning, drafting, revising and proof-reading, and being able to co-ordinate these processes over a span of time. Gillespie and Graham (2014) found an effect size of 0.43 for interventions which supported management of the writing process. In their analysis, process writing "consisted of students engaging in cycles of planning, drafting, revising, editing, and publishing their writing, sustained time for writing for authentic purposes and authentic audiences, and instruction conducted in mini-lessons to target students' writing needs as they arose" (Gillespie \& Graham, 2014, p. 457). Their finding that dictation was also a positive strategy (effect size 0.55 ) may well also link to the writing process. By having a scribe who captures the dictated text, a struggling writer is freed from the cognitively costly demands of transcription and orthography and may be more able to allocate cognitive attention to drafting and to evaluating the text. 
The value of strategy instruction recurs throughout the research, and it demonstrated the highest effect size (1.09) in Gillespie and Graham's metaanalysis. Many of the studies providing strategy instruction are about helping writers to manage the writing process (Danoff, Harris, \& Graham, 1993; Kiuhara, O'Neil, Hawken, \& Graham, 2012; Mason et al., 2011), and Garcia de CasoFuertes, Fidalgo-Redondo, Arias-Gundin, and Torrance (2010) argue that students with learning difficulties "can show marked improvements in the quality of texts they produce if they learn to strategically regulate the writing process" (2010, p. 77).

The third strand of instructional approaches, explicit and direct approaches, appears to draw on a differing body of research focused on supporting grammatical competence. These studies are not always focused on writing, however. What they have in common is direct instruction in aspects of expressive language where specific needs or weaknesses have been identified. Leonard, Camarata, Brown, \& Camarata (2004) designed a successful intervention to help children with SLI use third person singular or auxiliary is/was/are. Ebbels, van der Lely, and Dockrell (2007) targeted verb argument structure in students with SLI through direct instruction and achieved a greater rate of improvement in the intervention than in the control group.

Similarly, the use of visual strategies in the form of shapes, colours and arrows proved effective in helping older children master grammatical structures such as past tense formation (Ebbels, 2007). Saddler and Graham (2005) evaluated the efficacy of peer-assisted sentence-combining instruction on weaker writers, and concluded that this form of explicit instruction has a moderate impact on improving writing outcomes in adolescent students. Pertinent to the focus of this chapter, Ebbels (2014) suggests that whilst implicit approaches might be most effective for younger children, explicit approaches seem to be more effective in older children.

\section{Supporting Metalinguistic Development in Writing}

Explicit approaches which foster metalinguistic understanding about writing have formed the locus of two of our own studies, both with older adolescent writers. Whilst almost all language users develop a substantial body of implicit understanding of talk through their natural, everyday social interactions, metalinguistic understanding about writing may not develop so naturally. Although all writers draw on their social and reading experiences in order to write, specific metalinguistic understanding of how written texts are crafted and how metalinguistic choices at word, sentence and text level shape meaning 
seems less well-understood. Writing itself, of course, is an enterprise which is taught, and the research reviewed earlier in this chapter reiterates the importance of direct instruction. Our particular interest is in the potential value of developing students' explicit grammatical knowledge about writing, opening up for them access to a repertoire of possibilities for writing. Our theorisation of grammar as a tool for writing is not one which conceptualises grammar as a mechanism for error remediation, but one which conceptualises grammar as fundamentally about linguistic choice. Thus, explicit grammatical metalinguistic knowledge can be viewed not as "an end in itself, but a means of developing our awareness of the expressive richness of 'language in use'" (Crystal, 2004, p. 10). Therefore, our goal is to support writers in developing explicit metalinguistic knowledge of grammatical choices available to them, and to be able to select from this repertoire in their own written texts.

The first study (Jones, Myhill, \& Bailey, 2013; Myhill, Jones, Lines, \& Watson, 2012) used a mixed-methods design, including a randomised controlled trial with complementary qualitative data collection. Thirty-two mixed comprehensive schools, including children across the ability range, in the South-West of England and the Midlands were recruited and in each school, a class of Year 8 students, aged 12-13, formed the sample for the randomised controlled trial. Sixteen of these schools were randomly assigned to the intervention group and sixteen to the comparison group, thus there were no cases where an intervention class and a comparison class were from the same school. Baseline data relating to the school and teacher demographics, student performance data, and teacher grammatical subject knowledge were also collected. Qualitative data was collected each term of the three-term project and included classroom observations, teacher and student interviews, and writing samples from the project lessons. The purpose of this qualitative data was to provide a richer contextual understanding of how the intervention was employed by the teachers, experienced by the students and realised in classroom writing, to complement the statistical analysis which would indicate whether the intervention had any effect.

The study ran for one year and in each of the three terms, the intervention group taught a unit of work, running for three weeks, each focusing on a specific written genre (narrative fiction, argument, poetry). These units incorporated explicit teaching of grammatical constructions relevant to the genre being addressed: For example, how first and third person can alter viewpoint in narrative fiction, or how modal verbs can differently position the writer in an argument text. The comparison group taught the same three genres of writing, addressed the same teaching objectives, elicited the same written products, and had access to the same set of stimulus materials and resources. However, 
the intervention group had detailed teaching units, planned at the lesson level, in which grammar identified as relevant to the genre being addressed was explicitly taught.

A pre- and post-test design was adopted to determine the efficacy of the intervention. Using a cross-over design to reduce any possible test effect, two writing tasks were created, one inviting students to write about a personal fear, the other about a personal challenge. At the pre-test, half wrote about a personal fear and the other half about a personal challenge, and this was reversed for the post-test. Both tests were independently scored by a national assessment agency (Cambridge Assessment). The difference between the preand post-test at the end of the intervention showed that both groups had improved over the year, but that the intervention group had made significantly greater improvement. Overall, a two-sample t-test indicated a highly significant $(p<0.001)$ positive effect for the intervention in terms of improvement in writing attainment. Further multiple regression analyses suggested that the positive effect was mitigated by teachers' grammatical subject knowledge: an important finding given the new emphasis on grammar in the revised National Curriculum in England. In order to handle students' questions and to make meaningful connections for learners between grammatical choices and their effects in writing, teachers need confident grammatical subject knowledge.

A further finding was that able writers appeared to have benefitted more from the intervention than weaker writers. However, data analysis also indicated that able writers in the comparison group did not improve over the year, whereas the weaker writers in the comparison group did, albeit not at the same rate as those in the intervention. Thus, it is unclear from the data whether the intervention was better suited to the needs of able writers or whether the stronger positive effect was simply an artefact of the data and the limited improvement of able writers in the comparison group. Alternatively, able writers might be more capable of handling the grammatical metalanguage and the conceptual understanding underpinning them, and/or they may be better at transferring that knowledge into their own writing. The ambivalence of this finding that the intervention might be more beneficial for able writers led to the design of a follow-on study, specifically addressing whether this intervention, supporting the development of metalinguistic understanding of writing, was helpful for struggling writers. This study is described below. 


\section{Supporting Metalinguistic Development in Struggling Writers}

The key principle informing the first study was to develop metalinguistic understanding of writing by making explicit how particular linguistic structures supported particular writing genres. The aim was not to teach grammar, but to teach writing, and to equip young writers with metalinguistic understanding which supported linguistic decision-making and authorial control. The teaching materials were designed to meet the generic needs of year 8 writers, and although they did include both stretch and support activities to account for the differentiated needs of this group, they may have met the needs of more able writers more effectively than those of struggling writers. The follow-on study, therefore, focused more on learners' identified writing needs than on the genre demands of the writing task. The research design for this second study mirrored that of the earlier study, adopting a mixed methods approach including a quasi-experimental design and complementary qualitative data collection.

The follow-on study began with the systematic analysis of fifty writing samples of narrative writing graded as Level 3 or below in order to establish the writing needs of this group of struggling writers. Level 3 in England is a national achievement level and at age 11 the expectation is that students will achieve Level 4. Thus Level 3 represents a significant lag in writing attainment for a 13-year-old. The narratives were analysed both for their linguistic characteristics and for their overall composition and effect. Seven key writing needs were identified through this analysis:

- Limited use of internal sentence punctuation;

- Frequent omission of full stops or inaccuracy at sentence boundaries;

- Limited description through noun phrase expansion;

- Limited variety in sentence structure or length with a preponderance of long, complex sentences;

- Very plot-driven writing, with little establishment of character or setting;

- A tendency toward writing which reflected visual modes;

- A tendency to use language patterns reflecting oral rather than written genres.

In the light of this diagnostic analysis, an intervention was planned to cover approximately four weeks of teaching and designed using the pedagogical principles underpinning the earlier study. A key feature of this intervention was that it explored how a narrative was conveyed in a visual text and how this might transfer to the written mode. The aim was to show how detail in a visual 
mode might be made explicit in the written medium, particularly through the use of the noun phrase, the purpose being to appropriately target the linguistic features of text in a way that directly addressed the writing needs of these struggling secondary-aged writers. The visual resources used included videos depicting urban myths and a Bart Simpson graphic narrative. Through the use of these visual texts, students were supported in discussing how information, particularly in relation to how character is inferred through visual details in an image, needs to be conveyed through well-chosen words in writing. At the same time, the intervention highlighted how writers purposefully vary sentences; drawing attention to sentence length and purpose created an opportunity to focus on sentence boundary punctuation as part of the effective crafting of text. Finally, the intervention made explicit how a clear narrative structure can help young writers manage the relationship between the local and global elements of a text.

Seven schools were recruited to the study and two classes of students aged 12-13 from each school formed the sample. The groups were selected to represent low-attaining writers, typically attaining level 3 or low level 4 in the national assessment scales used in England at the time. Baseline data was collected to establish the similarity of the two groups: this comprised the writing level achieved by the students at age 11 (Key Stage 2) in the national tests of writing. Analysis of this data indicated that the intervention and comparison groups were well-matched at the start of the study, with both groups having a mean of Level 3.7 in the Key Stage 2 writing tests.

The pre- and post-test data shows a high attrition rate across the study, resulting from a fairly high rate of absenteeism amongst this group of weaker students both for the pre- and post-tests and during the taught elements of the intervention. This is an important point to note, not simply because of its potential effect on the statistical analysis, but because it is a reminder that this group of students are not homogenous in their profiles. Some of the struggling writers in these classes are students who struggle to master writing and may have learning difficulties; others are students whose poor attendance and disaffection with school limits their opportunities to learn. It is also impossible to tell from our data whether poor attendance and disaffection have developed from a sense of failure and increasing demotivation, or whether the poor attendance leads to failure and demotivation. Nonetheless, it is a reminder of the point noted earlier-that few studies, including our own, have taken sufficient account of the influence of motivation on the writing performance of struggling writers.

The pre- and post-data for the two groups reveals that, despite the very similar Key Stage 2 results, the comparison group scored more highly in the pre- 
TABLE 8.2 The mean scores of the two groups'pre-and post-test

\begin{tabular}{lccc}
\hline Group & Number & Pre-test score: mean & Post-test score: mean \\
\hline Comparison & 116 & $5 \cdot 4$ & $5 \cdot 9$ \\
Intervention & 127 & 4.6 & $5 \cdot 4$ \\
\hline
\end{tabular}

test than the intervention group. However, the gain for the intervention group was higher at 0.8 compared with 0.5 for the comparison.

Because the data represents students "nested" in classes who could not therefore be randomly assigned to comparison or intervention groups, an analysis of covariance (ANCOVA) was deemed most appropriate. When ANCOVA controls for the covariate it also removes some of the treatment effect, reducing the likelihood of obtaining a significant result. Before undertaking the ANCOVA to establish the statistical significance of this outcome, checks were made to ensure the relationships between the dependent variable and the covariate were the same for each group. A test of linearity indicated the relationship was linear and Levene's test of equality of error variances did not violate the assumption; but the test for homogeneity of the regression slopes showed a result that was just significant $(\mathrm{p}=0.047)$, thus marginally violating the assumption. Overall, however, these checks indicate no significant unequal relationship between the two groups. The subsequent ANCOVA test indicated that the different outcomes of the intervention and comparison group were just statistically significant when adjusted to two significant figures $(\mathrm{p}<0.05)$. This suggests caution should be exercised in claims made on the data, but that nevertheless there is a positive effect of the intervention on these struggling writers. This result may be influenced by the higher pre-test scores of the comparison group, by a teacher effect, or by the brevity of the intervention. To confirm these results, further studies are needed which address these issues in a larger scale study. Nonetheless, this study suggests that explicit instruction, drawing on grammatical features of writing, matched to learners' identified needs, may be an effective strategy to support writing development in struggling writers.

\section{Conclusions}

Reflecting on the implications of the Common Core State Standards (NGA/ CCsso, 2010) for students with learning disabilities, Graham and Harris (2013) 
argue that these standards are advantageous for this group of learners in establishing expectations of what should be achieved. In light of this, they offer clear recommendations for professional practice. They draw attention to the limitations of teachers' professional knowledge of writing development and recommend that teachers increase this knowledge. They also recommend that thought be given to establishing a classroom environment for writing which allows students with learning disabilities to flourish. Finally, they recommend that teachers draw on research evidence to inform their teaching of writing, both for students whose writing is developing along age-related trajectories and for students with learning disabilities (i.e., specific learning disorders).

However, perhaps the most salient point made in this chapter is that there is a real paucity of research evidence regarding the needs of older struggling writers, in the secondary phase of schooling, on which teachers can draw (a conclusion also drawn by Nelson and Gregg in Chapter 5 ). This probably reflects the fact that research in writing is itself still a maturing research field, particularly when compared with the very substantial and well-established field of research in reading. And within this, research in writing addressing adolescent or secondary-aged writers is a far smaller body of work than the research into how writing develops in the early years. More research is needed to determine whether there are particular differences between older students with SLI and those who lag behind age-related expectations in writing, and whether there are distinct instructional strategies or interventions which help these students. Future research, as noted earlier, should also investigate more thoroughly the issue of motivation in these older writers who are likely to have experienced a sense of their own "failure" at writing within the school system, particularly in jurisdictions with high-stakes assessment regimes.

\section{References}

Alamargot, D., \& Chanquoy, L. (2001). Through the models of writing. Dordrecht: Kluwer Academic Publishers.

Bereiter, C., \& Scardamalia, M. (1982). From conversation to composition: The role of instruction in a developmental process. In R. Glaser (Ed.), Advances in instructional psychology, Volume 2 (pp. 1-64). Hillsdale, NJ: Lawrence Erlbaum Associates.

Bereiter, C., \& Scardamalia, M. (1987). The Psychology of written composition. Hillsdale, $\mathrm{NJ}$ : Lawrence

Bialystok, E., \& Ryan, E.B. (1985). Towards a definition of metalinguistic skill. MerrillPalmer Quarterly, 31, 229-251.

Crystal, D. (2004). Rediscover grammar. London: Longman. 
Czerniewska, P. (1992). Learning about writing. Oxford: Blackwell.

Danoff, B., Harris, K., \& Graham, S. (1993). Incorporating strategy instruction within the writing process in the regular classroom: Effects on the writing of students with and without learning disabilities. Journal of Literacy Research, 25, 295-322.

De Milliano, I., van Gelderen, A., \& Sleegers, P. (2012). Patterns of cognitive self-regulation of adolescent struggling writers. Written Communication, 29(3), 3०3-325.

Department for Education (2012). What is the research evidence on writing? Research Report DFE-RR238 London: Department for Education

Dockrell, J.E., Lindsay, G., \& Connelly, V. (2009). The Impact of Specific Language Impairment on adolescents' written text. Exceptional Children, 75(4), 427-446.

Ebbels, S.H., van der Lely, H.K.J., \& Dockrell J.E. (2007). Intervention for verb argument structure in children with persistent SLI: A randomized control trial. Journal of Speech, Language, and Hearing Research, 50, 1330-1349.

Ebbels, S. (2007). Teaching grammar to school-aged children with specific language impairment using shape coding. Child Language and Therapy, 23, 67-93.

Ebbels, S. (2014). Effectiveness of intervention for grammar in school-aged children with primary language impairments: A review of the evidence. Child Language and Therapy, 30, 7-40.

Garcia, J-N., de Caso-Fuertes, A-M., Fidalgo-Redondo, R., Arias-Gundin, O., \& Torrance, M. (2010). Spanish research on writing instruction for students with learning disabilities. In C. Bazerman, R. Knut, K. Lunsford, S. McLeod, S. Null, P. Rogers, \& A. Stansell (Eds.), Traditions of writing research (pp. 71-81). London: Routledge.

Garcia, J-N., \& Fidalgo, R. (2008). Orchestration of writing processes and writing products: A comparison of sixth-grade students with and without learning disabilities. Learning Disabilities - A Contemporary Journal, 6(2), 77-98.

Gillespie, A., \& Graham, S. (2014). A meta-analysis of writing interventions for students with learning disabilities. Exceptional Children, 8o(4), 454-473.

Graham, S. (1990). The role of production factors in learning disabled students' compositions. Journal of Educational Psychology, 82, 781-791.

Graham, S., \& Weintraub, N. (1996) A review of handwriting research: Progress and prospects from 1980 and 1994. Educational Psychology Review, 8, 7-87.

Graham, S., \& Harris, K.R. (2013). Common Core State Standards, writing, and students with LD. Learning Disabilities Research \& Practice, 28, 28-37.

Hayes, J., \& Flower, L. (1980). Identifying the organization of writing process. In L. Gregg \& E. Steinberg (Eds.), Cognitive processes in writing (pp. 3-30). Hillsdale, NJ: Lawrence Erlbaum Associates.

Hooper, S., Swartz, C., Wakely, W., de Kruif, R., \& Montgomery, J. (2002). Executive functions in elementary school children with and without problems in written expression. Journal of Learning Disabilities, 35, 57-68.

Jones, D., \& Christensen, C.A. (1999). Relationship between automaticity in handwrit- 
ing and students' ability to generate written text. Journal of Educational Psychology, 91(1), 44-49.

Jones, S.M., Myhill, D.A., \& Bailey, T.C. (2013). Grammar for writing? An investigation into the effect of contextualised grammar teaching on student writing. Reading and Writing, 26(8), 1241-1263.

Kellogg, R.T. (1994). The Psychology of writing. Oxford: Oxford University Press.

Kellogg, R.T. (2008). Training writing skills: A cognitive developmental perspective. Journal of Writing Research, 1(1), 1-26.

Kinder, J., \& James, E. (2012). Dyslexia, authorial identity, and approaches to learning and writing: A mixed methods study. British Journal of Educational Psychology, 82(2), 289-307.

Kiuhara, S., O’Neil, R., Hawken, L., \& Graham, S. (2012). The effectiveness of teaching 1oth grade students with a disability a strategy for planning/drafting persuasive text. Exceptional Children, 78, 335-355.

Kress, G. (1994). Learning to write. London: Routledge.

Leonard, L.B., Camarata, S.M., Brown, B., \& Camarata, M.N. (2004). Tense and agreement in the speech of children with Specific Language Impairment: Patterns of generalization through intervention. Journal of Speech, Language, and Hearing Research, 47(6), 1363-1379.

Lum, J.A.G., \& Bavin, E.L. (2007). Analysis and control in children with SLI. Journal of Speech, Language, and Hearing Research, 50(6), 1618-1630.

MacArthur, C., \& Graham, S. (1987) Learning disabled students' composing with three methods: Handwriting, dictation and word processing. Journal of Special Education, 21, 22-42.

Mackie, C., \& Dockrell. J.E. (2004). The writing skills of children with SLI. Journal of Speech, Language, and Hearing Research, 47, 1469-1483.

Martlew, M. (1983). The psychology of written language: Developmental and educational perspectives. Chichester, U K: John Wiley.

Mason, L., Harris, K.R., \& Graham, S. (2011). Self-regulated strategy development for students with writing difficulties. Theory Into Practice, 50, 20-27.

Myhill, D., \& Fisher, R. (2010). Editorial:Writing development: Cognitive, sociocultural, linguistic perspectives. Journal of Research in Reading, 33(1), 1-3.

Myhill, D.A., Jones, S.M., Lines, H., \& Watson, A. (2012). Re-Thinking grammar: The impact of embedded grammar teaching on students' writing and students' metalinguistic understanding. Research Papers in Education, 27(2), 1-28.

National Commission on Writing in America's Schools and Colleges. (2003). The neglected " $R$ ": The need for a writing revolution. New York: College Board.

NGA/CCsso (National Governors Association/ Council of Chief State School Officers). (2010). Common Core State Standards. Washington, DC: Authors.

Prior, P. (2005). A Sociocultural theory of writing. In C. MacArthur, S. Graham, \& 
J. Fitzgerald (Eds.), The handbook of writing research (pp. 54-66). New York, Guilford Press.

Puranik, C. Lombardino, L., \& Altman, L. (2007). Writing through retellings: An exploratory study of language impaired and dyslexic populations. Reading and Writing, 20, 251-272.

Saddler, B., \& Graham, S. (2005). The effects of peer-assisted sentence combining instruction on the writing performance of more and less skilled young writers. Journal of Educational Psychology, 97, 43-54.

Santangelo, T., \& Olinghouse, N. (2009). Effective writing instruction for students who have writing difficulties. Focus on Exceptional Children, 42(4), 1-20.

Sawyer, C.E., Francis, M.E., \& Knight, E. (1992). Handwriting speed, specific learning difficulties and the GCSE. Educational Psychology in Practice, 8(2), 77-81.

Sharples, M. (1999). How we write: Writing as creative design. London: Routledge.

Stainthorp, R.W., \& Rauf, N. (2009). An investigation of the influence of the transcription skills of handwriting and spelling on the quality of text writing by girls and boys in Key Stage 2. Handwriting Today, 8, 8-13.

Troia, G. (2006). Writing instruction for students with learning disabilities. In C. MacArthur, S. Graham, \& J. Fitzgerald (Eds.). Handbook of writing research (pp. 324-336). New York: Guilford Press. 